\title{
Porcine dermis implants in soft-tissue reconstruction: current status
}

\author{
This article was published in the following Dove Press journal: \\ Biologics: Targets and Therapy \\ 10 March 2014 \\ Number of times this article has been viewed
}

\section{Neil J Smart' \\ Nicholas Bryan ${ }^{2}$ \\ John A Hunt ${ }^{2}$ \\ Ian R Daniels'}

'Exeter Surgical Health Services Research Unit, Royal Devon and Exeter Hospital, Exeter, UK; ${ }^{2}$ Clinical Engineering (UKCTE), The Institute of Ageing and Chronic Disease, University of Liverpool, Liverpool, UK

\begin{abstract}
Soft-tissue reconstruction for a variety of surgical conditions, such as abdominal wall hernia or pelvic organ prolapse, remains a challenge. There are numerous meshes available that may be simply categorized as either synthetic or biologic. Within biologic meshes, porcine dermal meshes have come to dominate the market. This review examines the current evidence for their use and the limitations of knowledge. Although there is increasing evidence to support their safety, long-term follow-up studies that support their efficacy are lacking. Numerous clinical trials that remain ongoing may help elucidate their precise role in soft-tissue reconstruction. Keywords: hernia, mesh, xenograft, biologic
\end{abstract}

\section{Introduction}

If we could artificially produce tissues of the density and toughness of fascia and tendon the secret of the radical cure of hernia would be discovered. [Theodor Billroth, 1878] ${ }^{1}$

It is over 130 years since Theodor Billroth, then professor of surgery at the University of Vienna, set out the challenge of soft-tissue reinforcement in a letter to one of his pupils. Since that time, both scientists and clinicians have endeavored to find a solution to a problem that remains one of the most challenging in the whole field of surgery. Soft-tissue defects of the abdominal and pelvic cavities, either primary (eg, inguinal hernia) or secondary (eg, incisional/ventral hernia), were traditionally repaired with sutures. The high rates of defect recurrence reported were unacceptable to both patients and surgeons. Early attempts at soft-tissue reinforcement were directed at hernia repair and utilized meshes made from a variety of metals, including silver, tantalum, and stainless steel. All metallic meshes ultimately failed due to a combination of metal fatigue, erosion, bowel fistulation, and, in the era before antibiotic availability, chronic infection. It was not until the seminal work of the American surgeon Francis Usher in the 1950s and 1960s that the modern era of soft-tissue reinforcement commenced. ${ }^{1}$

\section{Limitations of synthetic meshes}

The desirable characteristics of a prosthetic material suitable for soft-tissue reinforcement have been refined over the past 50 years and are now clearly defined in guidelines from the European Hernia Society. ${ }^{2}$ The fact that there are over 200 commercially available meshes on the worldwide market is an emphatic declaration that we do not yet have the "perfect" prosthetic material in our armamentarium. Bringing a degree of order and classification
Exeter Surgical Health Services Research Unit (HESRU), Royal Devon and Exeter Foundation Trust, Barrack Road, Exeter, Devon, UK, EX2 5DW Tel +44 I392402704

Email drneilsmart@hotmail.com 
to this bewildering array of meshes is an imperative. Although several classification systems based on an array of mesh characteristics exist, there is no universally agreed standardized system. The easiest approach is a dichotomous division into synthetic (derived from manufactured chemicals) or biologic (either allograft or xenograft) meshes.

Synthetic meshes have been used in soft-tissue reinforcement for over 50 years, in a wide array of clinical applications across a number of surgical specialties, from hernias of the abdominal wall to pelvic organ prolapse surgery. In many instances, such as inguinal hernia repair, their use has become the gold standard of care. They are not, however, without their adverse effects, such as chronic pain, foreign body sensation, and chronic infection. It is the poor outcome in terms of complications associated with the use of synthetic meshes in clean-contaminated or contaminated fields that has elicited caution about their use in such situations. ${ }^{3,4}$ Biologic prostheses derived from allo- or xenogeneic tissues have been proposed as a safer alternative to synthetics.

\section{Biologic meshes}

Biologic meshes were introduced in the 1990s and may be derived from human (allograft) or animal (xenograft; usually porcine or bovine) tissues. Dermis is the commonest tissue used because of the size of mesh that can be manufactured, but prostheses derived from intestinal submucosa and pericardium are also available. All biologic meshes essentially provide an extracellular scaffold necessary for the reconstruction of healthy tissue by allowing mass transport via ingrowth of new blood vessels and infiltration of native stromal cells including fibroblasts and myocytes that ultimately result in deposition of new extracellular matrix.

Allografts were the first biologic mesh type to be introduced in North America, initially dominating both the market and medical literature, but they were not available in the European Union due to regulatory restrictions. Consequently, xenografts were introduced because there was a more readily available source. This made xenografts cheaper to manufacture, and the subsequent lower costs and fewer regulatory restrictions meant that xenografts generally, and porcine dermis particularly, have come to dominate the market and medical literature worldwide over the last decade.

Porcine dermal prostheses are manufactured by tissue harvesting followed by a variety of proprietary decellularization and delipidation techniques. This leaves behind the three-dimensional collagen structure and constituent elastin fibers, which may then undergo further proprietary processing steps, such as supplemental cross-linking or removal of epitopes with alpha-galactosidase. Implants then undergo a terminal sterilization process. The differences between commonly available porcine dermal meshes are summarized in Table 1.

\section{The cross-linking debate}

Collagen is the predominant molecule present in porcine dermal meshes, since it is the major extracellular component of connective tissues. There are naturally occurring covalent cross-links both within and between the triple-helical polypeptide chain structure of collagen. These cross-links are formed by either an enzymatic pathway, which is catalyzed by lysyl oxidase, or by nonenzymatic processes (eg, radiation). Natural cross-links therefore exist in native collagen and function to stabilize the structure of the collagen protein, providing mechanical strength and protection from collagenase. ${ }^{5,6}$ In this respect, all porcine dermal meshes are naturally cross-linked. Some porcine dermal meshes undergo an additional chemical processing step to deliberately increase the amount of collagen cross-links, sometimes referred to as

Table I Overview of the most commonly used and available porcine dermal meshes

\begin{tabular}{|c|c|c|c|c|}
\hline Porcine dermis mesh & Manufacturer & Cross-linking & Sterilization & Size/thickness \\
\hline \multicolumn{5}{|l|}{ Cross-linked } \\
\hline Collamend ${ }^{\mathrm{TM}}$ & Bard, Covington, GA, USA & $\begin{array}{l}\text { Cross-linked collagen } \\
\text { and elastin (EDAC) }\end{array}$ & $\begin{array}{l}\text { Ethylene oxide } \\
\text { residuals }\end{array}$ & Size: $20.3 \times 25.4 \mathrm{~cm}$ \\
\hline Permacol ${ }^{\mathrm{TM}}$ & $\begin{array}{l}\text { Covidien, New Haven, } \\
\text { CT, USA }\end{array}$ & $\begin{array}{l}\text { Chemically cross-linked } \\
\text { (diisocyanate) }\end{array}$ & Gamma irradiation & $\begin{array}{l}\text { Size: } 28 \times 40 \mathrm{~cm} \\
\text { Thickness: } 0.5, \mathrm{I} \text {, and } 1.5 \mathrm{~mm}\end{array}$ \\
\hline \multicolumn{5}{|l|}{ Non-cross-linked } \\
\hline InteXen ${ }^{\mathrm{TM}}$ & AMS, Minnetonka, MN, USA & No & Ethylene oxide & \\
\hline Strattice $^{\mathrm{TM}}$ & $\begin{array}{l}\text { LifeCell Corporation, } \\
\text { Bridgewater, NJ, USA }\end{array}$ & No & E-beam & Size: $20 \times 20 \mathrm{~cm}$ \\
\hline$X C M$ & $\begin{array}{l}\text { Synthes, West Chester, } \\
\text { PA, USA }\end{array}$ & No & $\begin{array}{l}\text { Proprietary Optrix } \\
\text { processing }\end{array}$ & $\begin{array}{l}\text { Size: } 20 \times 30 \mathrm{~cm} \\
\text { Thickness: } 1.5 \pm 0.3 \mathrm{~mm}\end{array}$ \\
\hline XenMatrix $^{\mathrm{TM}}$ & Bard, Covington, GA, USA & No & E-beam & Size: $19 \times 35.5 \mathrm{~cm}$ \\
\hline
\end{tabular}


supplemental cross-linking. The role of cross-linking and the agents used have been reviewed in detail previously. ${ }^{7}$

The hypothesis that underpins the cross-linking debate is that supplemental cross-linking imparts a degree of resistance to collagenase activity, leading to retention of tensile strength after repetitive loading or a period of enzymatic (collagenase) degradation. ${ }^{8,9}$ This is of paramount importance in contaminated or infected fields, a situation in which porcine dermal meshes are advocated to be used in preference to synthetic meshes and in which they will be subjected to an increased level of collagenase produced by resident microorganisms in addition to activated leukocytes. The enhanced durability of cross-linked porcine dermal implants is purported to result in better clinical outcomes for hernia repair. ${ }^{10}$

Animal models have been used extensively to assess implantable materials generally and prostheses for soft-tissue reinforcement in particular, despite significant limitations. ${ }^{2}$ A recent systematic review of biologic meshes in animal studies concluded that supplemental cross-linking of collagen in tissue-based implants did not adversely affect the strength of the implant or its ability to support long-term ingrowth of native tissue. ${ }^{11}$ The limitations of animal models have, however, been clearly exposed recently by the comparison of the same two porcine dermal meshes, Permacol ${ }^{\mathrm{TM}}$ (supplemental cross-linked; Covidien, New Haven, CT, USA) and Strattice $^{\mathrm{TM}}$ (non-supplemental cross-linked; LifeCell Corporation, Bridgewater, NJ, USA), in different animal models, with startlingly differing results. ${ }^{12,13}$ Therefore, the extrapolation of results from animal data to the clinical context should be performed with caution. The choice of porcine dermal mesh by the surgeon should be based on the evidence available from clinical studies pertinent to the context in which it is being used.

\section{Incisional hernia/abdominal wall reconstruction}

Incisional hernias develop at the site of a surgical incision made to gain access to the abdominal cavity and where the abdominal wall failed to heal. Every surgical incision to the abdomen carries risk of hernia development, and estimates of incidence in the literature vary, with rates up to $30 \%$ reported. ${ }^{14}$ Most of these hernias enlarge over time, and the associated morbidity frequently leads to surgical correction. Recurrence rates are time dependent and increase with successive attempts at repair. ${ }^{15,16}$ It has been estimated that, each year, approximately 300,000 incisional hernias are repaired in Europe and 400,000 in the USA. ${ }^{17}$ The issue is that incisional hernias vary significantly in their size, complexity (domain/tissue loss, hernia content, infected or contaminated field), and range of patients in which they occur (degree of comorbidity).

The high cost of porcine dermal meshes compared to synthetic meshes means that their use in clean, simple cases cannot be justified. ${ }^{18}$ The Ventral Hernia Working Group made recommendations as to when to consider biologic mesh use. ${ }^{19}$ This simplified approach to classification of the complexity of hernia repair has enabled crude comparisons between reports of biologic mesh use, but ultimately did not address the thorny issue of what individual surgeons mean by use of the term "complex abdominal wall repair/ reconstruction." A recent international consensus document may help address that in future, but it remains unused so far. ${ }^{20}$ Similarly, the variability in outcome measure reporting that bedevils any comparison of the literature in this field has been addressed by another international consensus paper, but the recommendations have yet to find widespread adoption in the literature. ${ }^{21}$ Despite the plethora of recommendations and guidelines, there remains no consensus about when to use biologic materials in abdominal wall reconstruction among practicing surgeons in the USA. ${ }^{22}$

Numerous systematic reviews have been published on the use of biologic mesh in incisional hernia repair. Unfortunately, all biologic meshes have been grouped together, and the majority of the included data pertain to allografts. Many authors have questioned the conclusion that biologic meshes should form part of the surgical armamentarium, since the claim is not substantiated when subjected to scrutiny. ${ }^{23-25}$ Allografts are known to have high recurrence rates even in clean fields, and up to $100 \%$ in contaminated or infected fields, and their inclusion in the reviews has undoubtedly added bias. ${ }^{26,27}$ Studies comparing clinical outcomes for human and porcine dermal meshes are sparse, but report lower recurrence rates with porcine-derived products due to lower elastin content. ${ }^{28}$ Reviews specific to porcine dermal meshes are lacking, although some have reported outcomes for individual mesh brands, one review has suggested that cross-linked porcine dermal meshes have lower recurrence rates, particularly in infected or contaminated fields. ${ }^{29}$ The literature on porcine dermal mesh use in incisional hernia repair remains poor quality, having been dominated by single-institution retrospective case series until recently, and often in clean cases.

The Repair of Infected or Contaminated Hernias (RICH) study was the first to use a prospective, multicenter, singlearm trial design, and Strattice was used as the porcine dermal mesh of choice. ${ }^{30}$ Eighty patients had an open incisional 
hernia repair, with none carried out clean cases. The recurrence rate reported at 2 years was $28 \% .{ }^{30}$ The importance of surgical technique was also alluded to in this trial, with recurrence rates much lower for those with fascial closure compared with those without (23\% versus $44 \%$ ). Furthermore, mesh position in the abdominal wall may have played a role, with those undergoing retrorectus (beneath the rectus abdominis muscle) mesh placement having lower recurrence rates at 1 year despite significantly larger defects than in those patients with intraperitoneal mesh placement $(10 \%$ versus 30\%). ${ }^{31}$ Recent data from the Danish Hernia Database, a national population registry covering all mesh types, confirms that reoperation rates are lowest for the retrorectus mesh position (Figures 1 and 2). ${ }^{32}$

Numerous other single-institution series have followed the RICH study, most notably that of Rosen et al, who published their 5-year experience of abdominal wall reconstruction with biologic mesh. ${ }^{33}$ Of the 128 patients in their series, 102 were repaired with Strattice. Recurrence rates of $50 \%$ at 3 -year follow-up were reported. Other series reported rates of recurrence varying from $0 \%-43 \%$ at median follow-ups

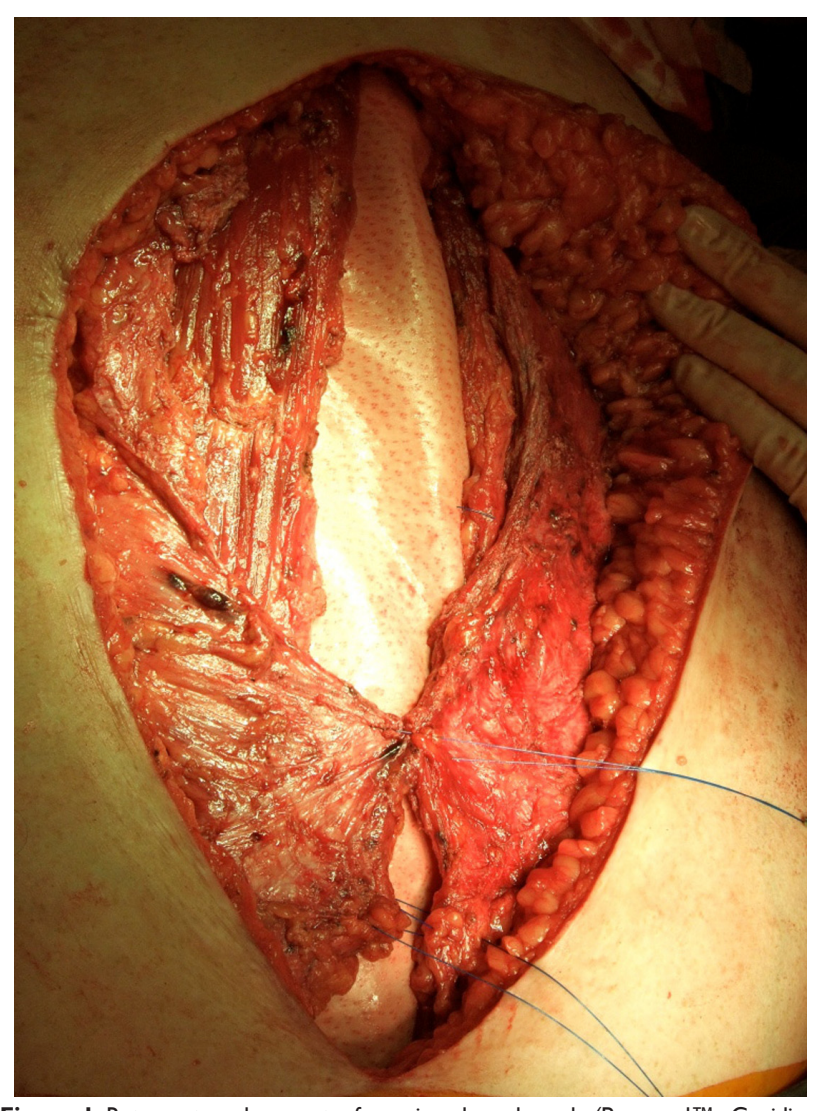

Figure I Retrorectus placement of porcine dermal mesh (Permacol ${ }^{\mathrm{TM}}$; Covidien, New Haven, CT, USA) in abdominal wall reconstruction for recurrent incisional hernia repair.

Notes: The anterior rectus sheath is being approximated with interrupted polypropylene sutures.

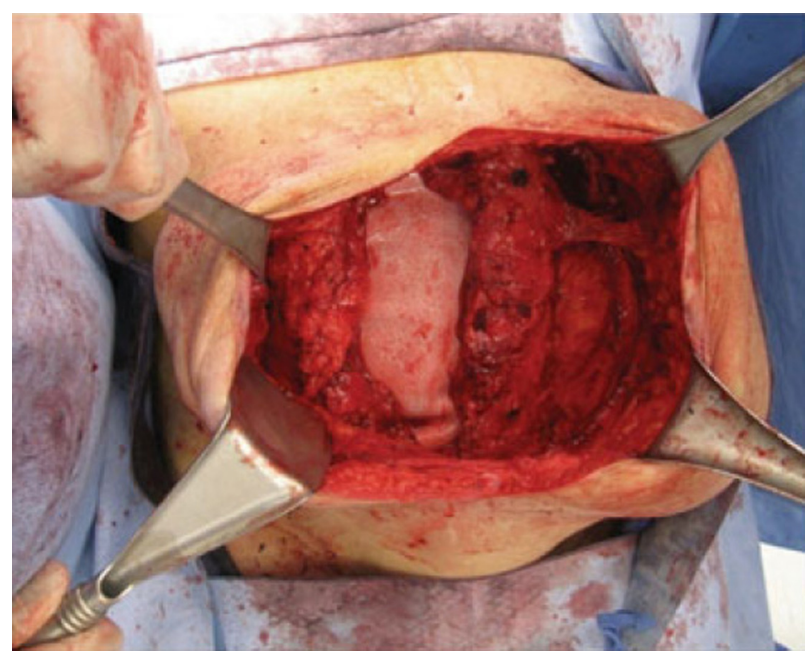

Figure 2 Underlay placement of porcine dermal mesh (Strattice ${ }^{\mathrm{TM}}$; LifeCell Corporation, Bridgewater, NJ, USA) in abdominal wall reconstruction for incisional hernia repair in a patient with a previous stoma. Reproduced from Guerra O, Maclin MM. Non-crosslinked porcine-derived acellular dermal matrix for the management of complex ventral abdominal wall hernias: a report of 45 cases. Hernia. Epub 2013 Aug 10.35

of less than 18 months and with considerable heterogeneity in terms of Ventral Hernia Working Group grade and surgical technique. ${ }^{34-36}$

Similar retrospective series have been published relating to the use of Permacol. The largest cohort is a multicenter study from 14 Kaiser Permanente hospitals with a prospective registry of hernia repairs. The group studied were again heterogeneous, but, of the 166 ventral hernias, the recurrence rate was $12 \%$ at a mean follow-up of just over 2 years, despite fascial closure being achieved in approximately one-half of patients. ${ }^{37}$ Superficially, this may seem much better than the data for Strattice, but recent data from the Mayo Clinic urge a note of caution, with a $66 \%$ recurrence rate noted with 5 years' follow-up, albeit with a preponderance of bridge repairs being utilized. ${ }^{38}$

Two small retrospective series with median follow-ups of 7 and 40 months have reported recurrence rates of $4.5 \%$ and $7.9 \%$, respectively, with use of XenMatrix ${ }^{\mathrm{TM}}$ (Bard, Covington, GA, USA). ${ }^{39,40}$ The majority of patients in both series had clean wounds. No new papers on the use of Collamend ${ }^{\mathrm{TM}}$ (Bard) have been published since a previous review by members of our group..$^{29}$ No clinical data on incisional hernia have been published for either InteXen ${ }^{\mathrm{TM}}$ (AMS, Minnetonka, MN, USA) or $\mathrm{XCM}^{\mathrm{TM}}$ (Synthes, West Chester, PA, USA).

High-quality prospective studies are still required to elucidate the precise role of porcine dermal meshes in abdominal wall incisional hernias. It is hoped that the new standardized definitions described above may help surgeons decide exactly which mesh to use in these challenging cases. Ongoing 
trials registered at clinicaltrials.gov seek to compare porcine dermal meshes in ventral hernia repair against a range of alternative surgical options, including: human dermis mesh (NCT01987700); synthetic mesh (NCT01746316); suture repair in infected fields (NCT01594450); and bioabsorbable meshes (NCT01794338). ${ }^{41-44}$ Further multicenter series, both retrospective and prospective, are also due to report on porcine dermal mesh performance in incisional hernia repair (NCT01268514, NCT01214252). ${ }^{45,46}$ Most intriguingly, however, is the prospect of histopathologic evaluation of explanted biologic meshes (NCT00484887) ${ }^{47}$ from humans, which is confined to the occasional case report thus far.

\section{Stomal hernia}

Parastomal hernia is a condition that is highly dependent on the surgical technique employed for repair for the prevention of recurrence. ${ }^{48}$ No head-to-head studies have compared mesh types in the context of repair, and the role of porcine dermal meshes has been confined to case series. ${ }^{37,49,50}$ One small randomized trial has demonstrated the efficacy of porcine dermal meshes for the prevention of parastomal hernias, ${ }^{51}$ but, in general, the infective complications with synthetic mesh in this context have been low. ${ }^{52}$ Since the optimal mesh and site of placement for parastomal hernia prophylaxis have not yet been determined, there are many ongoing randomized trials, including with porcine dermal mesh (NCT00771407). ${ }^{53}$

The incidence of incisional hernia at the site of a previous stoma may be as high as $30 \%$, with up to one-half of patients with a hernia requiring surgical repair. ${ }^{54}$ Prophylactic mesh placement at the time of stoma closure represents an infection risk, since the bowel would have been open at the site. Only one small case series has demonstrated the feasibility and safety of porcine dermal mesh placement at the time of stoma closure. ${ }^{55}$ A prospective randomized trial comparing the use of a prophylactic porcine dermal mesh to suture repair is ongoing (ISRCTN46330337).

\section{Perineal reconstruction following extralevator (EL) abdominoperineal excision (APE)}

In the original description of APE for rectal cancer, the English surgeon W Ernest Miles described wide excision of the levator musculature at their origins on the pelvic sidewall. ${ }^{56}$ This aspect of the technique has been overlooked by some surgeons who failed to appreciate the differences between the planes of dissection for anterior resection and APE and often leads to a surgical specimen narrowed at the level of the levator to create a "waist". This waist on the specimen increases the risk of tumor perforation and involved circumferential resection margin. The importance of a return to Miles' technique of removal of the levators has been emphasized recently by Holm et al and the procedure rebranded as an "extralevator APE" or "ELAPE". ${ }^{57}$ The problem is that perineal wound breakdown following conventional APE occurs in 35\%-65\% of patients, and rates of delayed healing at 6 months range from 17\%-26\%. ${ }^{58}$ ELAPE produces a large defect at the level of the pelvic floor, leaving only the ischioanal fat and skin to close the perineal wound. The optimal technique for closing the perineal defect is unknown, but a recent systematic review suggested that there was no difference in outcome between tissue flaps and biologic mesh. ${ }^{58}$ Most of the biologic mesh studies have used porcine dermis meshes (Permacol).

Two recent series have added further support to the use of porcine dermal meshes for perineal reconstruction, with low rates of perineal herniation and acceptable rates of complications consistent with previous studies (Figure 3). ${ }^{58-60}$ In the era of laparoscopic surgery, the routine use of rectus abdominis flaps seems counterintuitive and is likely to lead to longer-term abdominal wall problems. The acceptable outcomes associated with porcine dermal meshes offer an alternative solution,

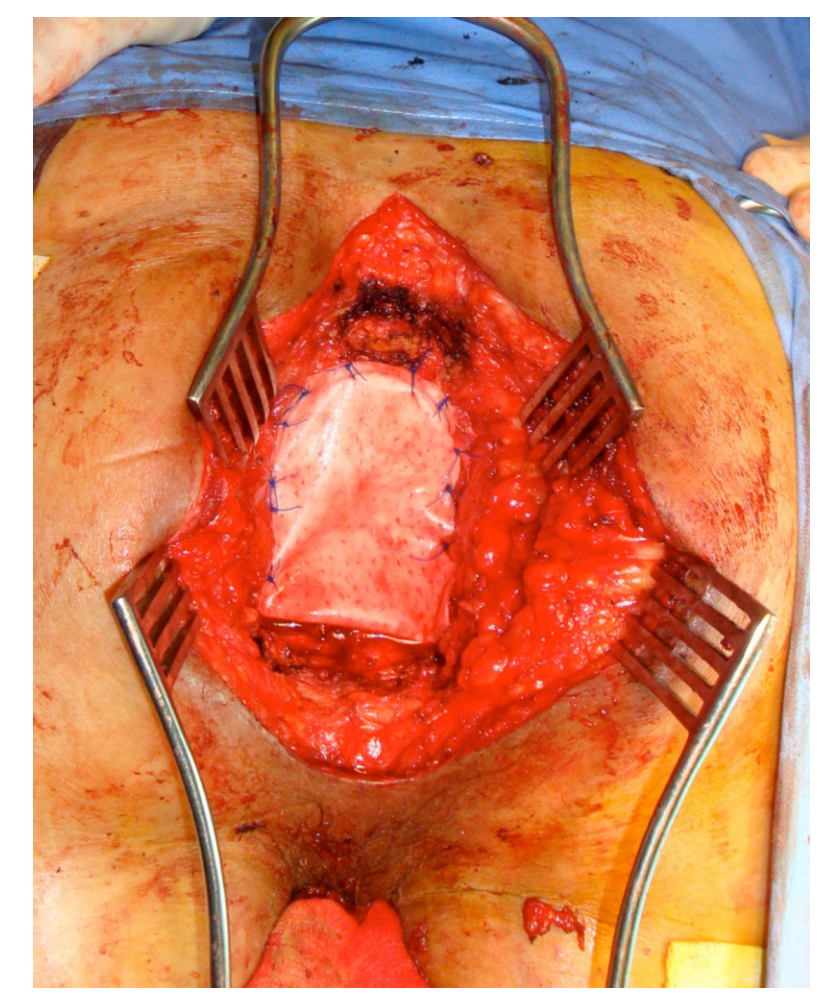

Figure 3 Perineal reconstruction with porcine dermal mesh (Permacol ${ }^{\mathrm{TM}}$; Covidien New Haven, CT, USA) following extralevator abdominoperineal excision for low rectal cancer.

Notes: The porcine dermal mesh has been sutured to the divided edges of the levators laterally and to the presacral fascia posteriorly. Anteriorly, the mesh is folded to form a " $U$ " shape that abuts the posterior wall of the vagina in females and the prostate in males. 
particularly if associated with cost savings due to shorter operating times, no need for plastic surgical input, and a reduction in hospital length of stay ${ }^{61}$ Further randomized trials (such as NCT01670851 and NCT01927497) $)^{62,63}$ may help surgeons decide on the optimum reconstructive technique but may offer no insight into the choice of porcine dermal mesh. What has puzzled many commentators is that, while bridging of defects in abdominal wall reconstruction has been demonstrated to lead to high rates of recurrence, in pelvic floor reconstruction following ELAPE, the defect is bridged out of necessity because of the loss of domain (levators), and yet similarly high rates of perineal herniation have not been observed. Admittedly, followup in most of the ELAPE series is short and the true long-term perineal herniation rate remains unknown.

\section{Laparoscopic ventral mesh rectopexy (VMR)}

Laparoscopic VMR is a surgical option for internal and external rectal prolapse with low perioperative morbidity and low recurrence rates. Since the original description by D'Hoore et al, ${ }^{64}$ it has become a favored approach in Europe. Use of synthetic mesh in the pelvis may be associated with complications such as fistulation, erosion, and dyspareunia, and this was highlighted by a US Food and Drug Administration warning in 2011 relating to transvaginal mesh placement. It has been suggested that porcine dermal meshes may avoid these complications, but the long-term outcome is uncertain, and debate continues as to which type of mesh is optimal. A recent systematic review demonstrated that biologic meshes were as effective as synthetic meshes for laparoscopic VMR and that reported complication rates were low for both, although duration of follow-up was noted to be short. ${ }^{65}$ Erosion rates for both types of mesh appear to be time dependent, and recent experience from an expert center in the management of such complications has been reported. ${ }^{66}$ Unfortunately, it has not been possible to determine the denominator in such series due to the tertiary referral nature of the work. Extrapolation of data from gynecological pelvic organ prolapse surgery may not be directly translatable due to differences in implantation techniques, but substantially lower rates of vaginal erosion occurred with biologic mesh than with synthetic mesh $(1.6 \%$ versus $6 \%) .{ }^{67}$

\section{Future perspectives}

Surgeons continue to face the challenge of soft-tissue reconstruction with an increasing armamentarium of prosthetics. How are they to choose which one to use? Some of the randomized trials mentioned above may provide some answers, but many trials (usually negative) are never published and therefore lead to bias in the literature. Furthermore, the trials needed to provide some of the answers would be large, complex to run, expensive, and risky for the device manufacturers. They are, essentially, unlikely ever to happen. Registry data may be an alternative source, but rely on meticulous data collection. Despite numerous attempts, the European Hernia Society has struggled to persuade surgeons to use its EuraHS database, which is similar to other voluntary schemes. Mandatory national databases, often associated with Scandinavian countries, can provide a rich source of data for common conditions, but they do not have the population size to provide the data on the plethora of meshes in existence, nor factor in which of the several outcomes (recurrence, reoperation rates, complications, quality of life, economic analyses) should be measured. The uncertainty regarding which mesh to use may be with us for some time.

One alternative solution may come from basic scientists rather than clinicians. Many have posed the question of whether it is reasonable to assume that one mesh will suffice for one clinical condition when patients are heterogeneous. The interaction between a material and a tissue is not biologically inanimate. Despite a material being mechanically appropriate to restore function in a particular tissue, this provides only a starting point for assessing long-term suitability as a material for reinforcement. After implantation, during the following hours to years, the body will attempt to use the material as a conduit to tissue regeneration, which may require its remodeling, cell infiltration, or removal. This process is unique to each individual and is governed by a wide array of factors, but, ultimately, the successful integration of a mesh requires a balance between the positive and negative components of the inflammatory response.

The first cells that interrogate the mesh are neutrophils, and their activation results in the release of reactive oxygen species, which can be measured in vitro. Bryan et al have measured neutrophil activation for a range of synthetic and biologic meshes ${ }^{68,69}$ and correlated degree of neutrophil activation to mesh performance in vivo using animal models. ${ }^{70,71}$ This raises the possibility of personalized implant choice in order to optimize outcome. Prospective trials of such techniques in humans are required, and may facilitate optimal use of the meshes that we have at our disposal.

\section{Conclusion}

We have not yet acquired a prosthetic that answers Billroth's challenge of soft-tissue reinforcement set out over 130 years ago. Porcine dermal meshes have an increasing evidence 
base regarding their safety, particularly in contaminated or infected fields, but long-term data to support their efficacy are still lacking in many instances and there are no clinical data that categorically support the use of one porcine dermal mesh over another.

\section{Disclosure}

NJS and IRD have received honoraria from Covidien for lecturing on colorectal and hernia surgery. NB and JAH have been funded research partners with Covidien for the development of implanted medical devices. The authors report no other conflicts of interest in this work.

\section{References}

1. Read RC. Milestones in the history of hernia surgery: prosthetic repair. Hernia. 2004;8(1):8-14.

2. Bringman S, Conze J, Cuccurullo D, et al. Hernia repair: the search for ideal meshes. Hernia. 2010;14(1):81-87.

3. van’t Riet M, de Vos van Steenwijk PJ, Bonjer HJ, Steyerberg EW, Jeekel J. Mesh repair for postoperative wound dehiscence in the presence of infection: is absorbable mesh safer than non-absorbable mesh? Hernia. 2007;11(5):409-413.

4. Choi JJ, Palaniappa NC, Dallas KB, Rudich TB, Colon MJ, Divino CM. Use of mesh during ventral hernia repair in clean-contaminated and contaminated cases: outcomes of 33,832 cases. Ann Surg. 2012;255(1): $176-180$

5. Sims TJ, Avery NC, Bailey AJ. Quantitative determination of collagen crosslinks. Methods Mol Biol. 2000;139:11-26.

6. Vater CA, Harris ED Jr, Siegel RC. Native cross-links in collagen fibrils induce resistance to human synovial collagenase. Biochem J. 1979;181(3):639-645.

7. Smart NJ, Bryan N, Hunt JA. A scientific evidence for the efficacy of biologic implants for soft tissue reconstruction. Colorectal Dis. 2012; 14 Suppl 3:1-6.

8. Pui CL, Tang ME, Annor AH, et al. Effect of repetitive loading on the mechanical properties of biological scaffold materials. J Am Coll Surg. 2012;215(2):216-228.

9. Annor AH, Tang ME, Pui CL, et al. Effect of enzymatic degradation on the mechanical properties of biological scaffold materials. Surg Endosc. 2012;26(10):2767-2778.

10. Smart NJ, Bloor S. Durability of biologic implants for use in hernia repair: a review. Surg Innov. 2012;19(3):221-229.

11. Smart NJ, Daniels IR, Marquez S. Supplemental cross-linking in tissue-based surgical implants for abdominal wall repair. Int J Surg. 2012;10(9):436-442.

12. Mulier KE, Nguyen AH, Delaney JP, Marquez S. Comparison of Permacol $^{\mathrm{TM}}$ and Strattice ${ }^{\mathrm{TM}}$ for the repair of abdominal wall defects. Hernia. 2011;15(3):315-319.

13. Cavallo JA, Greco SC, Liu J, Frisella MM, Deeken CR, Matthews BD. Remodeling characteristics and biomechanical properties of a crosslinked versus a non-crosslinked porcine dermis scaffolds in a porcine model of ventral hernia repair. Hernia. Epub March 13, 2013.

14. Eker HH, Hansson BM, Buunen M, et al. Laparoscopic vs open incisional hernia repair: a randomized clinical trial. JAMA Surg. 2013;148(3):259-263.

15. Burger JW, Luijendijk RW, Hop WC, Halm JA, Verdaasdonk EG, Jeekel J. Long-term follow-up of a randomized controlled trial of suture versus mesh repair of incisional hernia. Ann Surg. 2004;240(4):578-583.

16. Flum DR, Horvath K, Koepsell T. Have outcomes of incisional hernia repair improved with time? A population-based analysis. Ann Surg. 2003;237(1):129-135.
17. Sauerland S, Walgenbach M, Habermalz B, Seiler CM, Miserez M. Laparoscopic versus open surgical techniques for ventral or incisional hernia repair. Cochrane Database Syst Rev. 2011;(3):CD007781.

18. Shankaran V, Weber DJ, Reed RL, Luchette FA. A review of available prosthetics for ventral hernia repair. Ann Surg. 2011;253(1):16-26.

19. Breuing K, Butler CE, Ferzoco S, et al. Incisional ventral hernias: review of the literature and recommendations regarding the grading and technique of repair. Surgery. 2010;148(3):544-558.

20. Slater NJ, Montgomery A, Berrevoet F, et al. Criteria for definition of a complex abdominal wall hernia. Hernia. Epub October 23, 2013.

21. Muysoms FE, Deerenberg EB, Peeters E, et al. Recommendations for reporting outcome results in abdominal wall repair: results of a Consensus meeting in Palermo, Italy, June 28-30, 2012. Hernia. 2013;17(4):423-433.

22. Harth KC, Krpata DM, Chawla A, Blatnik JA, Halaweish I, Rosen MJ. Biologic mesh use practice patterns in abdominal wall reconstruction: a lack of consensus among surgeons. Hernia. 2013;17(1):13-20.

23. Primus FE, Harris HW. A critical review of biologic mesh use in ventral hernia repairs under contaminated conditions. Hernia. 2013;17(1): 21-30.

24. Harris HW. Biologic mesh for ventral hernia repair: a cautionary tale. Ann Surg. 2013;257(6):997-998.

25. Petter-Puchner AH, Dietz UA. Biological implants in abdominal wall repair. Br J Surg. 2013;100(8):987-988.

26. Ko JH, Salvay DM, Paul BC, Wang EC, Dumanian GA. Soft polypropylene mesh, but not cadaveric dermis, significantly improves outcomes in midline hernia repairs using the components separation technique. Plast Reconstr Surg. 2009;124(3):836-847.

27. de Moya MA, Dunham M, Inaba K, et al. Long-term outcome of acellular dermal matrix when used for large traumatic open abdomen. J Trauma. 2008;65(2):349-353.

28. Henry CR, Bradburn E, Moyer KE. Complex abdominal wall reconstruction: an outcomes review. Ann Plast Surg. 2013;71(3): 266-268.

29. Smart NJ, Marshall M, Daniels IR. Biological meshes: a review of their use in abdominal wall hernia repairs. Surgeon. 2012;10(3):159-171.

30. Itani KM, Rosen M, Vargo D, Awad SS, Denoto G 3rd, Butler CE; RICH Study Group. Prospective study of single-stage repair of contaminated hernias using a biologic porcine tissue matrix: the RICH Study. Surgery. 2012;152(3):498-505.

31. Rosen MJ, Denoto G, Itani KM, et al. Evaluation of surgical outcomes of retro-rectus versus intraperitoneal reinforcement with bio-prosthetic mesh in the repair of contaminated ventral hernias. Hernia. 2013;17(1):31-35.

32. Helgstrand F, Rosenberg J, Kehlet H, Jorgensen LN, Bisgaard T. Nationwide prospective study of outcomes after elective incisional hernia repair. J Am Coll Surg. 2013;216(2):217-228.

33. Rosen MJ, Krpata DM, Ermlich B, Blatnik JA. A 5-year clinical experience with single-staged repairs of infected and contaminated abdominal wall defects utilizing biologic mesh. Ann Surg. 2013;257(6): 991-996.

34. Patel KM, Nahabedian MY, Gatti M, Bhanot P. Indications and outcomes following complex abdominal reconstruction with component separation combined with porcine acellular dermal matrix reinforcement. Ann Plast Surg. 2012;69(4):394-398.

35. Guerra O, Maclin MM. Non-crosslinked porcine-derived acellular dermal matrix for the management of complex ventral abdominal wall hernias: a report of 45 cases. Hernia. Epub August 10, 2013.

36. Zerbib P, Caiazzo R, Piessen G, et al. Outcome in porcine acellular dermal matrix reinforcement of infected abdominal wall defects: a prospective study. Hernia. Epub September 19, 2013.

37. Cheng AW, Abbas MA, Tejirian T. Outcome of abdominal wall hernia repair with Permacol(TM) biologic mesh. Am Surg. 2013;79(10): 992-996.

38. Abdelfatah MM, Rostambeigi N, Podgaetz E, Sarr MG. Long-term outcomes ( $>5$-year follow-up) with porcine acellular dermal matrix $\left(\right.$ Permacol $\left.^{\mathrm{TM}}\right)$ in incisional hernias at risk for infection. Hernia. Epub October 16, 2013. 
39. Alicuben ET, Demeester SR. Onlay ventral hernia repairs using porcine noncross-linked dermal biologic mesh. Hernia. Epub February 12, 2013.

40. Diaz-Siso JR, Bueno EM, Pomahac B. Abdominal wall reconstruction using a non-cross-linked porcine dermal scaffold: a follow-up study. Hernia. 2013;17(1):37-44.

41. Musculoskeletal Transplant Foundation. Multi-Center Study To Examine The Use Of Flex HD ${ }^{\circledR}$ And Strattice In The Repair Of Large Abdominal Wall Hernias. Available from: http://clinicaltrials.gov/ct2/show/NCT01987700. NLM identifier: NCT01987700. Accessed January 21, 2014.

42. University Hospitals of Cleveland. Biologic Mesh Versus Synthetic Mesh in Repair of Ventral Hernias. Available from: http://clinicaltrials. gov/show/NCT01746316. NLM identifier: NCT01746316. Accessed January 21, 2014

43. University Hospital, Lille. Biological Meshes in Infected Fields: a Randomized Controlled Trial (SIMBIOSE). Available from: http:// clinicaltrials.gov/show/NCT01594450. NLM identifier: NCT01594450. Accessed January 21, 2014.

44. Carolinas Healthcare System. The Use of Biologic Mesh vs Bioabsorbable Mesh During Ventral Hernia Repair in At-risk Patients. Available from: http://clinicaltrials.gov/ct2/show/NCT01794338. NLM identifier: NCT01794338. Accessed January 21, 2014.

45. Covidien. ENHANCE: A Prospective EvaluatioN of Permacol ${ }^{\mathrm{TM}}$ in tHe Repair of Complex AbdomiNal Wall CasEs. Available from: http:// clinicaltrials.gov/show/NCT01268514. NLM identifier: NCT01268514. Accessed January 21, 2014.

46. Covidien. A Retrospective Study Evaluating the Use of Permacol Surgical Implant in the Repair of Abdominal Wall Defects. Available from: http://clinicaltrials.gov/show/NCT01214252. NLM identifier: NCT01214252. Accessed January 21, 2014.

47. University of Missouri-Columbia. Characterization of Explanted Hernia Meshes From Human Subjects: A Multi-Center, Prospective Study. Available from: http://clinicaltrials.gov/show/NCT00484887. NLM identifier: NCT00484887. Accessed January 21, 2014.

48. Hansson BM, Slater NJ, van der Velden AS, et al. Surgical techniques for parastomal hernia repair: a systematic review of the literature. Ann Surg. 2012;255(4):685-695.

49. Smart NJ, Velineni R, Khan D, Daniels IR. Parastomal hernia repair outcomes in relation to stoma site with diisocyanate cross-linked acellular porcine dermal collagen mesh. Hernia. 2011;15(4):433-437.

50. Slater NJ, Hansson BM, Buyne OR, Hendriks T, Bleichrodt RP. Repair of parastomal hernias with biologic grafts: a systematic review. J Gastrointest Surg. 2011;15(7):1252-1258.

51. Hammond TM, Huang A, Prosser K, Frye JN, Williams NS. Parastomal hernia prevention using a novel collagen implant: a randomised controlled phase 1 study. Hernia. 2008;12(5):475-481.

52. Shabbir J, Chaudhary BN, Dawson R. A systematic review on the use of prophylactic mesh during primary stoma formation to prevent parastomal hernia formation. Colorectal Dis. 2012;14(8):931-936.

53. LifeCell. Parastomal Reinforcement With Strattice (PriSm). Available from: http://clinicaltrials.gov/show/NCT00771407. NLM identifier: NCT00771407. Accessed January 21, 2014.

54. BhanguA, Nepogodiev D, Futaba K; West Midlands Research Collaborative. Systematic review and meta-analysis of the incidence of incisional hernia at the site of stoma closure. World J Surg. 2012;36(5): 973-983.

55. Bhangu A, Futaba K, Patel A, Pinkney T, Morton D. Reinforcement of closure of stoma site using a biological mesh. Tech Coloproctol. Epub April 3, 2013.

Biologics: Targets \& Therapy

\section{Publish your work in this journal}

Biologics: Targets \& Therapy is an international, peer-reviewed journal focusing on the patho-physiological rationale for and clinical application of Biologic agents in the management of autoimmune diseases, cancers or other pathologies where a molecular target can be identified. This journal is indexed on PubMed Central, CAS, EMBase, Scopus
56. Miles WE. A method of performing abdominoperineal excision for carcinoma of the rectum and of the terminal portion of the pelvic colon. Lancet. 1908;2:1812-1813.

57. Holm T, Ljung A, Haggmark T, Jurell G, Lagergren J. Extended abdominoperineal resection with gluteus maximus flap reconstruction of the pelvic floor for rectal cancer. Br J Surg. 2007;94:232-238.

58. Foster JD, Pathak S, Smart NJ, et al. Reconstruction of the perineum following extralevator abdominoperineal excision for carcinoma of the lower rectum: a systematic review. Colorectal Dis. 2012;14(9): 1052-1059.

59. Kiim Jensen K, Rashid L, Pilsgaard B, Mølle P, Wille-Jørgensen P. Pelvic floor reconstruction with a biological mesh after extralevator abdominoperineal excision leads to low wound complication and perineal hernia rates with minor movement limitations. Colorectal Dis. Epub November 20, 2013.

60. Kipling SL, Young K, Foster JD, et al. Laparoscopic extralevator abdominoperineal excision of the rectum: short-term outcomes of a prospective case series. Tech Coloproctol. Epub October 1, 2013.

61. Marshall MJ, Smart NJ, Daniels IR. Biologic meshes in perineal reconstruction following extra-levator abdominoperineal excision (elAPE). Colorectal Dis. 2012;14 Suppl 3:12-18.

62. University Hospitals, Leicester. Perineal Reconstruction Following eLAPE and Simultaneous Stoma Sublay Reinforcement (PRESSUR). Available from: http://clinicaltrials.gov/show/NCT01670851. NLM identifier: NCT01670851. Accessed January 21, 2014.

63. Academisch Medisch Centrum - Universiteit van Amsterdam (AMCUvA). Biological Mesh Closure of the Pelvic Floor After Extralevator Abdomino Perineal Resection for Rectal Cancer (BIOPEX). Available from: http://clinicaltrials.gov/show/NCT01927497. NLM identifier: NCT01927497. Accessed January 21, 2014.

64. D'Hoore A, Cadoni R, Penninckx F. Long-term outcome of laparoscopic ventral rectopexy for total rectal prolapse. Br J Surg. 2004;91: $1500-1505$.

65. Smart NJ, Pathak S, Boorman P, Daniels IR. Synthetic or biological mesh use in laparoscopic ventral mesh rectopexy - a systematic review. Colorectal Dis. 2013;15(6):650-654.

66. Badrek-Al Amoudi AH, Greenslade GL, Dixon AR. How to deal with complications after laparoscopic ventral mesh rectopexy: lessons learnt from a tertiary referral centre. Colorectal Dis. 2013;15(6):707-712.

67. Wong KS, Nguyen JN, White T, et al. Adverse events associated with pelvic organ prolapse surgeries that use implants. Obstet Gynecol. 2013;122(6):1239-1245.

68. Bryan N, Ahswin H, Smart NJ, Bayon Y, Hunt JA. In vitro activation of human leukocytes in response to contact with synthetic hernia meshes. Clin Biochem. 2012;45(9):672-676.

69. Bryan N, Ashwin H, Smart N, Bayon Y, Scarborough N, Hunt JA. The innate oxygen dependant immune pathway as a sensitive parameter to predict the performance of biological graft materials. Biomaterials. 2012;33(27):6380-6392.

70. Bryan N, Ahswin H, Smart N, Bayon Y, Wohlert S, Hunt JA. The in vivo evaluation of tissue-based biomaterials in a rat full-thickness abdominal wall defect model. J Biomed Mater Res B Appl Biomater. Epub October 24, 2013.

71. Bryan N, Ashwin H, Chen R, et al. Evaluation of six synthetic surgical meshes implanted subcutaneously in a rat model. J Tissue Eng Regen Med. Epub October 7, 2013.

and the Elsevier Bibliographic databases. The manuscript management system is completely online and includes a very quick and fair peerreview system, which is all easy to use. Visit http://www.dovepress com/testimonials.php to read real quotes from published authors.

\section{Dovepress}

